УДК 330

\title{
ПОВЫШЕНИЕ ЭФФЕКТИВНОСТИ ИСПОЛЬЗОВАНИЯ ОСНОВНЫХ СРЕДСТВ АВИАПРЕДПРИЯТИЯ ЗА СЧЁТ ПРИМЕНЕНИЯ НЕЙРОТЕХНОЛОГИЙ И ТЕХНОЛОГИИ ВIGDАТА
}

Фомина Ирина Александровна к.э.н., доцент

Сливинский Денис Валерьевич к.э.Н., Доцент

Мосягин Егор Михайлович ФГБОУ ВО «Санкт-Петербургский государственный университет гражданской авиации»

\begin{abstract}
Аннотация: В условиях предстоящего изменения промышленнотехнологического уклада и, в связи с этим, усиливающейся тенденции к цифровизации процессов работы внутри предприятий, авиапредприятия, как наиболее технически оснащённые, могут стать одними из главных бенефициаров от внедрения новых технологий в процесс эксплуатации высокотехнологичных основных средств.
\end{abstract}

Ключевые слова: авиапредприятие, авиакомпания, современные технологии, техника.

INCREASING THE EFFICIENCY OF USE OF FIXED ASSETS OF AIRLINES BY USING NEUROTECHNOLOGIES AND BIG DATA TECHNOLOGIES ON THE EXAMPLE OF «S7 AIRLINES»

\section{Fomina Irina Aleksandrovna Slivinskii Denis Valerievich Mosiagin Egor Mikhaylovich}

\begin{abstract}
: in the context of the upcoming change in the industrial and technological structure and, in this regard, the growing trend towards digitalization of work processes within enterprises, aviation enterprises, as the most technically equipped, can become one of the main beneficiaries from the introduction of new technologies into the operation of high-tech fixed assets.
\end{abstract}

Key words: aviation enterprises, airline, modern technologies, equipment. 
Историю экономического развития мира, при более детальном её изучении можно разделить на так называемые «технологические уклады» промежутки времени, эпохи, технологическое и экономическое развитие в которых характеризуется некоторой общностью применяемых идей, методов и технологий. Так, в данный момент мы переживаем смену технологического уклада и переходим в новый, шестой уклад [1]. Для шестого технологического уклада характерны такие черты, как:

1. Цифровизация данных, оборачиваемых в процессе деятельности компаний.

2. Сетецентричность вычислительных мощностей и наделение вычислительными мощностями того оборудования, которое раньше такими возможностями не обладало.

3. Применение алгоритмов глубокого изучения, больших данных и искусственного интеллекта для обработки получаемых данных.

Все эти характерные черты наступающего технологического уклада в интегральном своём действии стремятся заменить человека на предприятии настолько, насколько это только возможно.

Изменения, происходящие или только предстоящие вследствие смены технологического уклада, обширны и самым кардинальным образом повлияют на все сферы деятельности человека. Противится какому-либо предприятию этим изменениям невозможно, по крайней мере, продолжительное время, и даже опасно, так как предприятия принявшие происходящие изменения и раньше вступившие в игру по новым правилам нового технологического уклада смогут раньше организовать свою работу по-новому и выйти из состояния нестабильности, которое характерно при любом процессе изменения внешней среды и конъюнктуры, и получить от данных глобальных изменений выгоду, в то время, как предприятия, отказавшиеся от затратного процесса реформирования своей технологической деятельности, в будущем начнут отставать от своих конкурентов [2].

На первых этапах инновационные технологии шестого технологического уклада в большей степени применима к техническим структурам работы предприятия, нежели к социальным. Иными словами, на первых порах нового технологического уклада человеку отводятся роли, требующие социального взаимодействия и стратегического планирования, а все технические вопросы, в том числе вопросы использования основных средств, коими в авиационной отрасли является сложное оборудование, отдаются машинам, причём машинам в широком смысле слова - не только роботам, но и алгоритмам.

Эксплуатация высокотехнологичного, сложного оборудования сопряжена с большой работой по отслеживанию текущего состояния механизмов, 11 
расчётам износа и определению параметров будущей эксплуатации этого оборудования. Особенно это характерно для авиационной сферы, где вопросы прогнозирования работоспособности оборудования являются критически важными, и требующими особых организационных мер. Таким образом, в стремлении достичь приемлемого уровня безопасности эксплуатации своих основных средств, авиационные предприятия вкладывают большие средства в найм работников соответствующего уровня для работы с техникой, которая и является основными средствами для авиакомпаний, организацию рабочих мест для этих работников, создание контролирующих механизмов и системы переподготовки персонала.

Сокращение данных издержек при помощи инновационных технологий, сопутствующих шестому технологическому укладу, может стать одним из главных конкурентных преимуществ для авиакомпаний в ближайшее время.

Учитывая низкую маржинальность бизнесов в авиационной отрасли и высокую конкуренцию, характерную для авиационной отрасли, имплементация новых методов организации работы по содержанию и эксплуатации основных средств в ближайшем будущем является крайне вероятной. Ввиду всего вышеперечисленного авиационная отрасль с большой долей вероятности может стать пионером, одной из первых отраслей, которая начнёт инновационную трансформацию.

Основными инновационными технологиями нового технологического уклада являются:

1. Большие данные.

2. Нейротехнологии и искусственный интеллект.

3. Системы распределенного реестра.

4. Квантовые технологии.

5. Новые производственные технологии.

6. Промышленный интернет.

7. Компоненты робототехники и сенсорика.

8. Технологии беспроводной связи; технологии виртуальной и дополненной реальностей.

Наиболее развитыми на данный момент являются технологии «больших данных», систем распределённого реестра (блокчейн) и промышленный интернет (сети 5G), поэтому эти технологии являются первостепенными для внедрения их в деятельность предприятий.

Исходя из всех вышеописанных условий, а именно - насыщенность авиапредприятий сложным, высокотехнологичным оборудованием, которое выступает в роли непосредственно основных средств производства, низкая маржинальность и высокая конкуренция в отрасли авиационных перевозок, 
тенденция к цифровизации и назревающая необходимость перехода к новым принципам организации работы предприятий, в свете нового технологического уклада, а также развитость и актуальность на данный момент таких технологий, как $5 \mathrm{G}$ сети, блокчейн и алгоритмы анализа данных на основе искусственных нейросетей, перспективным видится интеграция инновационных технологий именно в авиапредприятиях.

Из всего спектра российский авиакомпаний, претендующих на роль пионера внедрения в свою работу инновационных технологий, больше всего подходит авиакомпания «S7 Airlines», ввиду того, что авиакомпания Сибирь является крупнейшей частной авиакомпанией в России, что, безусловно, даёт ей большую свободу действий в вопросах новых подходов к организации своей деятельности, постоянно растущий пассажиропоток, высокая занятость кресел, новый парк воздушных судов и хорошие финансовые результаты на протяжении многих лет свидетельствуют о грамотной работе менеджмента и о наличии ресурсов для развития инновационных технологий и внедрения их в свою деятельность [3]. В том числе политика руководства компании направлена на создание имиджа современной, высокотехнологичной авиакомпании, в свете этого действительное внедрение новых подходов в работе с основными средствами будет работать на создание такого представление у клиентов и партнёров, что в перспективе повысит рыночную стоимость компании.

Дальнейшее развитие авиакомпании должно интенсифицироваться именно на основании и с учётом требований и тенденций нового технологического уклада, с применением в первую очередь технологий неейросетевого анализа, 5Gсетей и технологии распределённого реестра данных (блокчейн). Самым вероятным сценарием развития событий, удовлетворяющим всем вышеперечисленным условиям, является внедрение так называемого управления полным жизненным циклом любого изделия (PLM) [2]. Управление жизненным циклом - это электронное, программное отражение эксплуатации любого изделия, с возможностью расчёта всех нагрузок и прогнозирования работоспособности этого изделия в будущем. Создаётся как бы цифровой двойник оборудования, который выступает макетом для квалифицированного персонала, работающего с этим оборудованием. Так, при планировании ремонта или технического обслуживания, персонал в первую очередь отрабатывает все планируемые действия на электронном двойнике, оптимизируя тем самым свои предстоящие действия уже на реальном оборудовании, такой подход многократно снижает вероятность ошибки в технологическом процессе обслуживания оборудования.

Первичным звеном создания электронного двойника является оцифровка всех параметров работы оборудования, для этого используется множество 
датчиков, которые замеряют все необходимые показатели и отправляют их в единый для данной единицы оборудования центр, где все полученные данные обрабатывается при помощи множества алгоритмов, в первую очередь при помощи, так называемых, нейросетеевых алгоритмов.

Нейросетевые алгоритмы, в том числе технология «больших данных» обрабатывает информацию таким образом, что в ходе анализа полученных данных самостоятельно обучается правильно их интерпретировать, в случае с программами, использующими нейронные сети не требуется трудозатратная наладка программы с привлечением большого числа программистов, что безусловно является преимуществом использования данных программ. Но для корректной работы нейросетевых алгоритмов необходим большой массив данных, передача которых от оборудования должна осуществляется регулярно, и в этом может помочь технология сетей передачи данных пятого поколения $5 \mathrm{G}$, которая специально разрабатывалась для развития и поддержки интернета вещей (internetofthings), сети с огромным количеством пользователей, которым необходимо постоянно поддерживать связь, именно такой сетью может является множество датчиков, снимающих показания с высокотехнологичного оборудования, использующегося в качестве основных средств авиапредприятиями.

Сохранность же полученных данных позволяет осуществить технология распределённого реестра данных (блокчейн), использующая хеш-функцию при обработке данных и многократно резервирующая значение этой хеш-функции на множестве носителей, подключённых к единой сети, этим множеством может выступать множество датчиков, подключённых к сети 5G.

Таким образом, самый вероятный сценарий имплементации новых подходов работы, соответствующих шестому технологическому укладу, заключается в организации множества цифровых двойников оборудования, выступающего в роли основных средств, с применением таких технологий как «блокчейн», «нейросети» и «5G сети» именно на воздушном транспорте, в частности на оборудовании авиакомпании «S7 Airlines».

\section{Список литературы}

1. Тебекин А.В. Технологический уклад как основа социальноэкономического развития общества: инновационные аспекты исследования [Электронный pecypc]. - Режим доступа: https://cyberleninka.ru/article/n/ tehnologicheskiy-uklad-kak-osnova-sotsialnoekonomicheskogo-razvitiya-obschestvainnovatsionnye-aspekty-issledovaniya/viewer, свободный, (дата обращения 30.08.2020); 
2. Юдина Т.Н. Цифровизация как тенденция современного развития экономики Российской Федерации: proYcontra. [Электронный ресурс]. - Режим доступа: https://cyberleninka.ru/article/n/tsifrovizatsiya-kak-tendentsiyasovremennogo-razvitiya-ekonomiki-rossiyskoy-federatsii-pro-y-contra/viewer , свободный, (дата обращения 30.08.2020);

3. Официальный сайт a/к S7, информация о флоте воздушных судов, финансовых результатах и политике авиакомпании [Электронный ресурс]. Режим доступа : https://www.s7.ru/ru/about/s7-airlines.dot , свободный (дата обращения 30.08.2020).

(C) И.А. Фомина, Д.В. Сливинский, Е.М. Мосягин 